operation. The entire analysis is based on the assumption that catalyst dilution effects are homogeneous and deterministic in character. It should be borne in mind that in the larger framework of systems analysis, design of a reactor involving catalyst dilution has to be undertaken within an overall economic domain.

\section{Nomenclature}

$A=$ preexponential factor, $1 . / \mathrm{mt}$

$A_{\mathrm{w}}=$ wall heat transfer area in fluid bed reactor, $\mathrm{cm}^{2}$

$A^{*}=$ ratio of preexponential factors

$a=$ radius of plug flow reactor, $\mathrm{cm}$

$C_{\mathrm{p}}=$ heat capacity of fluid, $\mathrm{cal} / \mathrm{g} \mathrm{K}$

$E=$ activation energy, cal/g-mol

$h=$ film heat transfer coefficient, cal $/ \mathrm{mt} \mathrm{cm}^{2} \mathrm{~K}$

$j=$ maximum adiabatic temperature rise, $\mathrm{K}$

$k_{\mathrm{r}}=$ pseudohomogeneous reaction rate constant, $1 . / \mathrm{mt}$

$k_{\mathrm{r}}=$ heterogeneous reaction rate constant, $\mathrm{g}-\mathrm{mol} / \mathrm{mt} \mathrm{cm}^{2}$ atm

$p=$ reactant partial pressure, atm

$q=$ flow rate, $\mathrm{ml} / \mathrm{mt}$

$Q^{+}=$heat generation function, dimensionless

$Q^{-}=$heat abstraction function, dimensionless

$r=$ reaction rate, $\mathrm{g}-\mathrm{mol} / \mathrm{mt} \mathrm{ml}$

$\bar{r}=$ reaction rate, $1 . / \mathrm{mt}$

$R=$ gas constant, l. atm $/ \mathrm{g}-\mathrm{mol} \mathrm{K}$

$S_{\mathrm{g}}=$ catalyst surface area, $\mathrm{cm}^{2} / \mathrm{g}$

$\mathrm{St}=$ Stanton number, $h / C_{\mathrm{p}} \cdot \rho v_{0}$, dimensionless

$T=$ temperature, $\mathrm{K}$

$v=$ linear velocity, $\mathrm{cm} / \mathrm{mt}$

$v^{*}=$ reduced velocity, dimensionless

$x=$ conversion

$z=$ reactor length
Greek Letters

$\rho=$ fluid density, $\mathrm{g} / \mathrm{ml}$

$\rho_{\mathrm{p}}=$ catalyst density, $\mathrm{g} / \mathrm{ml}$

$\epsilon=$ voids in reactor

$\alpha=$ catalyst dilution factor

$\theta=$ holding time, $\mathrm{mt}$

$\beta=$ dimensionless, $h A_{\mathrm{w}} / q \rho C_{\mathrm{p}}$

$\tau=$ locus

$\Delta H_{\mathrm{r}}=$ heat of reaction, $\mathrm{cal} / \mathrm{g}-\mathrm{mol}$

$\Delta S^{\circ}=$ standard reaction entropy, cal/g-mol K

Subscripts

$0=$ feed condition

$\mathrm{A}=$ reactant $\mathrm{A}$

$\mathrm{b}=$ bulk

$\mathrm{m}=$ optimum

$\mathrm{e}=$ equilibrium

$c=$ coolant

* = lower bound

$\phi=$ entrance condition

$n=$ reactor number

hs $=$ hot-spot

Superscripts

$'=$ reverse reaction

* = upper bound

Literature Cited

Aris, R., "Introduction to the Analysis of Chemical Reactors", Prentice-Hall Inc., Englewood Cliffs, N.J., 1965.

Barkelew, C. H., Chem. Eng. Prog. Symp. Ser, 55, No. 25 (1959)

Calderbank, P. H., Brit. Chem. Eng., 14, 1199 (1969).

Luss, D., Amundson, N. R., AIChE J., 14, 211 (1968)

van Den Bleek, et al., Chem. Eng. Sci, 24, 681 (1969).

\title{
Formation of Dry Hydrogen Chloride by Means of Pyrolysis of the By-product of Vinyl Chloride Monomer Manufacturing
}

\author{
P. R. R. Venhuizen, H. Bosch, ${ }^{*}$ and P. Mars \\ Department of Chemistry, Twente University of Technology, Enschede, The Netherlands
}

\begin{abstract}
A process is described for the pyrolysis of the by-products of vinyl chloride manufacture. By means of a batchwise combined gas- and liquid-phase pyrolysis at 1 atm about half of the chlorine present in the by-product could be recovered as dry hydrogen chloride, about $20 \%$ as vinyl chloride, and about $30 \%$ as chlorinated $\mathrm{C}_{2}$ hydrocarbons; less than $1 \%$ remained in the solid residue.
\end{abstract}

\section{Introduction}

Production of vinyl chloride monomer (VCM) gives rise to about 2 wt $\%$ of by-products. This VCM by-product, containing about $70 \mathrm{wt} \% \mathrm{Cl}$, consists of partially chlorinated $\mathrm{C}_{2}$ and $\mathrm{C}_{4}$ compounds (especially 1,2-dichloroethane (EDC) and 1,1,2-trichloroethane) and higher molecular polymers and tars. Disposing of this by-product by dumping at sea is unacceptable and is prohibited in many areas. Therefore VCM by-product incineration systems are being installed to produce hydrochloric acid for industrial use. In some cases, anhydrous hydrogen chloride is recovered for recycling to the oxychlorination unit within the VCM pro- cess. Other research workers point out that part of the VCM by-product can be used as a feed supplement in perchlorination processes (Stauffer, 1972).

As an alternative for incineration, we studied the pyrolysis of VCM by-product which has the advantage of producing less corrosive, anhydrous hydrogen chloride in a more concentrated product stream. Our objective was to develop a simple procedure for the VCM by-product pyrolysis, with a high yield of hydrogen chloride or other valuable products. For this reason we reviewed the literature on thermal decomposition of individual chlorinated hydrocarbons. On this basis we designed our experiments which have been 
carried out batchwise on a bench scale. For our investigation we used a sample of a mixture of by-products from various units of a VCM plant utilizing Stauffer technology: a so-called balanced route consisting of chlorine addition and oxychlorination of ethene, followed by pyrolysis of EDC to VCM.

\section{Choice of Reactor System and Procedure}

2.1. Literature on Pyrolytic Dehydrochlorination. Most polychlorinated $\mathrm{C}_{1}$ and $\mathrm{C}_{2}$ hydrocarbons are capable of decomposing via a radical-chain mechanism. The reactions are mostly first order and often show a marked induction period for the buildup of a propagating radical concentration. The rate of the radical-type decomposition is affected by the packing of the reaction vessel. Initiation and termination of the radical-chains are believed to take place on the walls of the reaction vessel (Barton, 1949; Kapralova and Semenov, 1963). Only in "seasoned" reaction vessels in which a fine coating of carbonized material from previous decompositions had formed on the walls, was it possible to obtain reproducible experimental results.

One of the best-known examples of a radical-chain decomposition is the gas-phase pyrolysis of EDC to vinyl chloride, an excellent review of which is given by Shelton et al. (1971). For the uninhibited reaction the following mechanism is proposed (Barton and Howlett, 1949)

$$
\text { initiation: } \quad \mathrm{ClCH}_{2} \mathrm{CH}_{2} \mathrm{Cl} \rightarrow \mathrm{ClCH}_{2} \mathrm{CH}_{2} \cdot+\mathrm{Cl} \text {. }
$$

propagation: $\mathrm{Cl} \cdot+\mathrm{ClCH}_{2} \mathrm{CH}_{2} \mathrm{Cl} \rightarrow \mathrm{ClCH}_{2} \mathrm{CHCl}+\mathrm{HCl}$

$$
\mathrm{ClCH}_{2} \mathrm{CHCl} \rightarrow \mathrm{CH}_{2}=\mathrm{CHCl}+\mathrm{Cl} \text {. }
$$

$$
\text { termination: } \mathrm{Cl} \cdot+\mathrm{ClCH}_{2} \mathrm{CHCl} \rightarrow \mathrm{Cl}_{2} \mathrm{CHCH}_{2} \mathrm{Cl}
$$

In many cases, besides the radical-chain reactions a unimolecular mechanism may operate at the same time (Swinbourne, 1972). It is often found that the rate of radical-type decomposition is decreased by the presence of small amounts of radical-chain inhibitors such as propene and aromatics due to the formation of relatively stable, unreactive radicals. At higher concentrations of these inhibitors unimolecular decomposition prevails over that via radicals.

Most chlorinated hydrocarbons such as chloroethane, with a $\beta$-hydrogen atom but no $\beta$-chlorine atom, do not exhibit radical-chain decomposition at all, because the radical that would be involved in the propagation step can only continue the chain through hydrogen transfer (autoinhibition, Maccoll, 1969). These compounds decompose via a much slower unimolecular mechanism, characterized by first-order kinetics without an induction period; the reaction rate is unaffected by packing the reaction vessel or by the presence of radical-chain inhibitors. Figure 1 gives Arrhenius plots from literature data of some uncatalyzed gasphase dehydrochlorinations.

The activation in the unimolecular mechanism involves charge separation in the carbon-chlorine bond. Consideration of this process provides an understanding of the relative order of reactivity in the pyrolysis. Considering chloroethane as the parent molecule to which substituent groups are attached, $\alpha$-methylation results in a $\sim 200$-fold increase in the dehydrochlorination rate at $350^{\circ} \mathrm{C}$ for each $\alpha$-methyl group substituted (see Figure 1), $\beta$-methylation gives a $\sim 2$-fold increase for each $\beta$-methyl group, $\alpha$-chlorination in a $\sim 5$-fold increase for each $\alpha-\mathrm{Cl}$ group, and $\beta$-chlorination a corresponding decrease for each $\beta-\mathrm{Cl}$ group substituted.

For the heterogeneously catalyzed decomposition of gaseous chlorinated hydrocarbons on Pyrex glass, silica, alumina, alkali halides, and related solids a similar polar type mechanism has been proposed as for the unimolecular de-

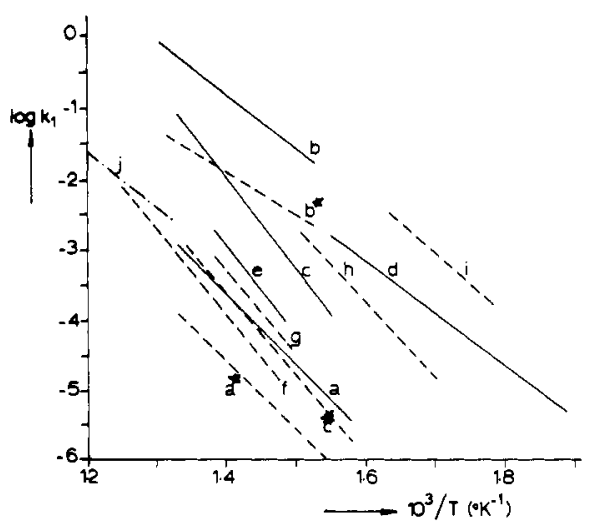

Figure 1. Arrhenius plots of various pyrolytic dehydrochlorinations: --, radical-chain decomposition; -...-, unimolecular de compositions; *, studied under conditions of maximal inhibition. The compounds and the respective references are as follows: (a) 1,2-dichloroethane, Barton and Howlett (1949); (b) 1,1,2-trichloroethane, Teramoto et al. (1964); (c) 1,2-dichloroethene, Goodall and Howlett (1956); (d) 1,1,2,2-tetrachloroethane, Barton and Howlett (1951); (e) 1,4-dichlorobutane, Williams (1953); (f) chloroethane, Hoolbrook and March (1967); (g) 1-chlorobutane, Hartmann et al. (1964); (h) 2-chlorobutane, Heydtmann and Rinck (1961); (i) tert-butyl chloride, Barton and Onyon (1949); and (j) VCM by-product sample, this investigation.

composition (Moller et al., 1971). A fast deactivation of the catalyst has been reported in most cases, due to fouling of the surface and reaction of hydrogen chloride with the catalyst.

Hydrogen-containing chloroethanes can also be dehydrochlorinated in the liquid phase $\left(35-100^{\circ} \mathrm{C}\right)$ in the presence of metal chlorides possessing strong Lewis acid characteristics (Prins, 1937), such as $\mathrm{AlCl}_{3}$ and $\mathrm{FeCl}_{3}$. Products are hydrogen chloride, chloroethylenes, chlorobutanes and -butenes and, especially in the case of dichloroethanes, complex polymeric products (Zilberman et al., 1967). Rapid polymerization of vinyl chloride was found to occur at 20 ${ }^{\circ} \mathrm{C}$ in a slurry of metal chloride in EDC (Rothan and Sims, 1970).

The pyrolytic breakdown of polymers containing chloride is also of interest (Berticat et al., 1970; Kelen et al., 1974). Polyvinyl chloride (PVC) undergoes dehyrochlorination at $200^{\circ} \mathrm{C}$, leaving tars and a graphite-like residue; polyvinylidiene chloride rapidly gives off one molecule of hydrogen chloride per monomer unit at $170^{\circ} \mathrm{C}$ and a second molecule at $700-800^{\circ} \mathrm{C}$, giving an amorphous carbon residue. Chlorinated PVC of the formula (-CHCl-CHCl-) performs dehydrochlorination upon heating (one molecule of hydrogen chloride at $270-300^{\circ} \mathrm{C}$, a second at $300-800$ ${ }^{\circ} \mathrm{C}$ ), leaving a porous carbon residue having a high surface area $\left(400-1300 \mathrm{~m}^{2} / \mathrm{g}\right)$.

2.2 Selection of Apparatus and Design of Experiments. Considering the kinetic data of the dehydrochlorination of the various compounds and especially the fact that the lighter components of the liquid VCM by-product, having mostly primary chlorine atoms, pyrolyze at higher temperatures than the heavier molecules with more secondary chlorine atoms, we chose a combination of gas- and liquid-phase pyrolysis for our batchwise experiments.

After vaporization at $95-150^{\circ} \mathrm{C}$, the tar-free vapor of the lighter components decomposes under conditions that coke formation is limited. For this decomposition no catalyst is needed. The products of this gas-phase pyrolysis are partially condensed: the condensate containing unreacted material and unsaturated products is recycled to the remaining VCM by-product in the evaporation vessel, and the gaseous hydrogen chloride and other light products are collected. 


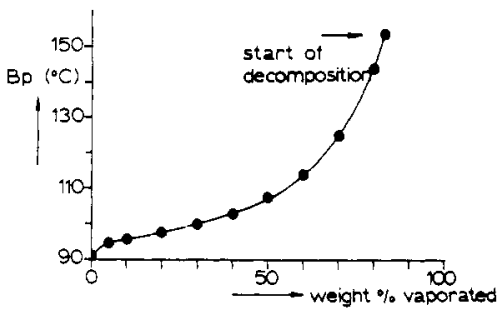

Figure 2. Boiling range of the VCM by-product sample at $1 \mathrm{~atm}$.

In the liquid phase we try, under the influence of a catalyst, for example $\mathrm{AlCl}_{3}$, to accomplish the formation of higher molecular compounds, which have the advantage of containing more secondary and tertiary $\mathrm{Cl}$ atoms for relatively easy dehydrochlorination. As in the second part of the experiment the temperature of the liquid phase increases, these newly formed compounds with high molecular weight, together with the polymers and tars already present in the VCM by-product, will undergo dehydrochlorination in the liquid phase.

Three types of experimental runs were performed: (I) pyrolysis without recycling of the condensate from the partial condensor; (II) pyrolysis with recycling of the condensate; and (III) pyrolysis with recycling and addition of a polymerization promoting catalyst to the VCM by-product.

\section{Experimental Section}

3.1 Material. The VCM by-product sample is a black liquid, density $1.33 \mathrm{~g} \mathrm{~cm}^{-3}$, elementary analysis by weight: $70.2 \% \mathrm{Cl}, 25.7 \% \mathrm{C}$, and $3.6 \% \mathrm{H}$. The boiling range is shown in Figure 2. Above $154^{\circ} \mathrm{C}$ the remaining components begin to decompose. Table I gives the analysis of the sample of the mixture of by-products from various units of a VCM plant.

3.2 Apparatus. The gas-phase pyrolysis was performed in a quartz glass reactor of $38 \mathrm{~mm}$ i.d., $600 \mathrm{~mm}$ in length. A sketch of the entire apparatus is given in Figure 3 . The lower $200 \mathrm{~mm}$ of the gas-phase reactor were packed with Raschig-rings; the following reaction zone had a temperature profile of $\pm 5{ }^{\circ} \mathrm{C}$, measured through a thermocouple channel in the reactor. The Pyrex glass evaporator, as well as liquid phase reactor, was heated electrically with a constant energy supply. The temperature of both reactors was recorded continuously. Organic products were collected in a cold trap, kept at $-60^{\circ} \mathrm{C}$ with dry ice and acetone.

3.3 Procedure. Nitrogen was used for flushing the apparatus before every run. During operation the pressure in the system was $2-5 \mathrm{cmHg}$ above atmospheric pressure.

Some preliminary runs were performed in order to determine the limitations of the procedure. A batch weight of $146 \mathrm{~g}$ ( $1.2 \mathrm{~mol})$ of VCM by-product was used. The energy supply to the vaporization vessel was adjusted to obtain a stable vapor feed to the gas-phase reactor of about $0.5 \mathrm{~mol}$ $\mathrm{h}^{-1}$. The gas-phase pyrolysis was conducted between 340 and $600^{\circ} \mathrm{C}$, but $T_{\mathrm{GR}}=545^{\circ} \mathrm{C}$ was taken for most of the runs to ensure a high conversion without excessive tar formation.

Between the runs, the gas-phase reactor was not thoroughly cleaned. Only the material that could be loosened from the reactor wall by shaking the Raschig rings up and down was recovered.

3.4 Analysis. Hydrogen chloride was efficiently adsorbed in a well stirred aqueous alkaline solution and titrated stepwise with a $4 \mathrm{~N} \mathrm{KOH}$ solution, using methyl red as the indicator. The analysis of the VCM by-product sample and the liquid products of the pyrolysis was performed by means of a gas chromatograph with katharometer detection (Urone et al., 1962). Two columns were used: the first
Table I. Analysis of the VCM By-product Sample

\begin{tabular}{|c|c|c|c|}
\hline$\underset{\mathrm{mol}^{-1}}{\mathrm{~g}}$ & Compound & $\mathrm{Bp},{ }^{\circ} \mathrm{C}, 1 \mathrm{~atm}$ & $\begin{array}{l}\text { Wt \% } \\
\text { of the } \\
\text { VCM } \\
\text { by-pro- } \\
\text { duct }\end{array}$ \\
\hline 99 & 1,2-Dichloroethane & 84 & 37 \\
\hline 133 & 1,1,2-Trichloroethane & 113 & \\
\hline 99 & 1,1-Dichloroethane & 57 & \\
\hline 133 & $1,1,1$-Trichloroethane & 74 & \\
\hline 131 & Trichloroethene & 87 & \\
\hline 168 & Tetrachloroethane $(2 \times)$ & 129,146 & \\
\hline 202 & Pentachloroethane & 162 & total: 20 \\
\hline 127 & Dichlorobutane $(3 x)$ & $124,131,161$ & \\
\hline 161 & Trichlorobutane $(2 \times)$ & 150,165 & \\
\hline 125 & 1,4-Dichlorobutene-2 & 152 & \\
\hline & Polymers and tars & & \\
\hline
\end{tabular}

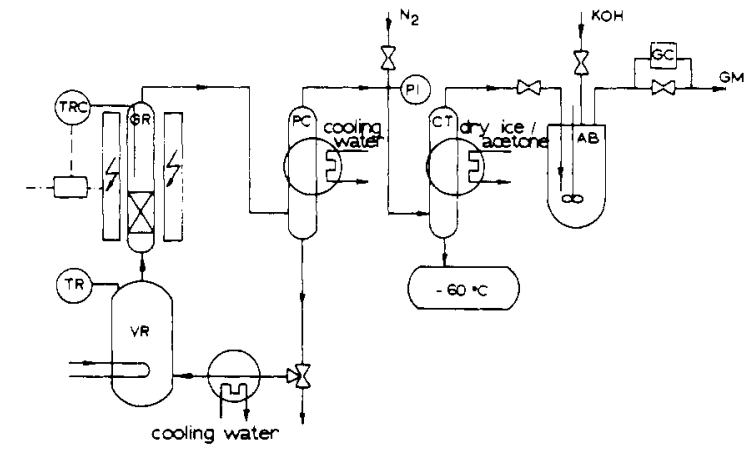

Figure 3. Experimental setup: VR = evaporator/liquid phase reactor $\left(400 \mathrm{~cm}^{3}\right) ; \mathrm{GR}=$ gas-phase reactor (i.d. $38 \mathrm{~mm}$, length 600 $\mathrm{mm}) ; \mathrm{PC}=$ partial condensor, $\mathrm{CT}=$ cold trap $\left(200 \mathrm{~cm}^{3}\right) ; \mathrm{AB}=$ $\mathrm{HCl}$ absorption and titration vessel $\left(200 \mathrm{~cm}^{3}\right) ; \mathrm{GC}=$ gas chromatograph; GM = gas metering device.

one $6 \mathrm{~mm}$ i.d., $3.5 \mathrm{~m}$ long, packed with $10 \%$ SE 30 on $60-80$ mesh Chromosorb W, column temperature $48^{\circ} \mathrm{C}$, carrier gas argon, $30 \mathrm{ml} / \mathrm{min}$, which gave good separation of the trans-and cis-1,2-dichloroethene; the other one $1 / 4$ in. i.d., $2.25 \mathrm{~m}$ long, packed with $24 \%$ paraffin on $60-80$ mesh Chromosorb W, column temperature $92^{\circ} \mathrm{C}$ (injection $250^{\circ} \mathrm{C}$ ), carrier gas hydrogen, $60 \mathrm{ml} / \mathrm{min}$, gave good results for higher boiling components.

Before injection, the liquid from the cold trap was mixed with cooled carbon tetrachloride in the weight ratio 1:4 to lower the partial pressure of the volatile components. The collected gaseous products of the pyrolysis were analyzed on the above described SE 30 column and for the analyses of traces of hydrogen and $\mathrm{C}_{1}-\mathrm{C}_{2}$ hydrocarbons, a Porapak $\mathrm{Q}$ column was used, $6 \mathrm{~mm}$ i.d., $3 \mathrm{~m}$ long, temperature $48^{\circ} \mathrm{C}$, and carrier gas argon, $30 \mathrm{ml} / \mathrm{min}$.

In all cases the sum of the analyzed components added up to $95-110 \%$. For unknown components having a longer retention time on the paraffin column than 1,1,2-trichloroethane, we assumed an average molecular weight of $150 \mathrm{~g}$ $\mathrm{mol}^{-1}$.

In all our experiments $80-90 \%$ of the starting material was recovered from the apparatus (compare Figure 6). Apart from losses due to holdup and incomplete recovery of residues, the main cause was slip of organic products through the cold trap into the hydrogen chloride absorption fluid. The solubility of chlorinated hydrocarbon in water is low (VCM : $0.11,1,1$-dichloroethene : $0.021 \mathrm{~g} / 100 \mathrm{~g}$ of $\mathrm{H}_{2} \mathrm{O}, 25^{\circ} \mathrm{C}$ ), but in the presence of inorganic salts various reactions may occur. The aqueous absorption fluid became very turbid during each experiment.

As mentioned before, three types of experimental runs have been performed. In a type I experiment the pyrolysis is a once-through operation, without the complication of a 


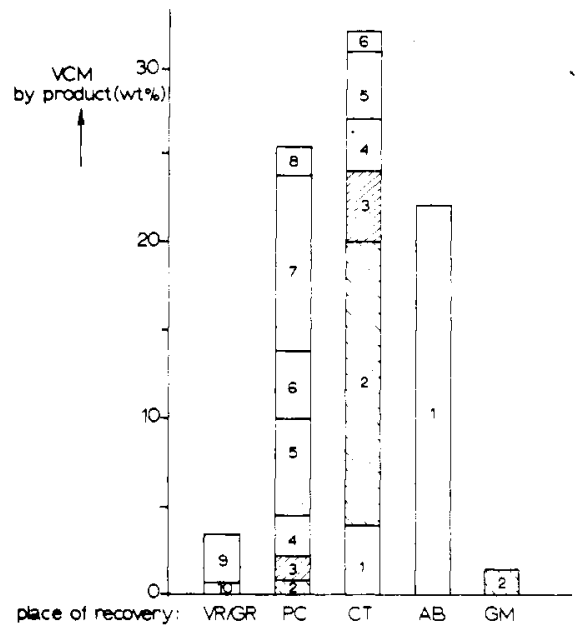

Figure 4. Product distribution as collected in a type $I$ experiment. $T_{\mathrm{VR}}=95-600{ }^{\circ} \mathrm{C}, T_{\mathrm{GR}}=545^{\circ} \mathrm{C}, T_{\mathrm{PC}}=15^{\circ} \mathrm{C}$. Letter code: see caption of Figure 3. 1 = hydrogen chloride, $2=$ vinyl chloride, $3=$ 1,1-dichloroethene, $4=$ trans-1,2-dichloroethene, $5=\mathrm{cis}$-1,2-dichloroethene, $6=1,2$-dichloroethane, $7=1,1,2$-trichloroethane, 8 $=$ unknown heavy material, $9=$ solid residue $\mathrm{VR}, 10=$ recovered from GR.

recycle stream. The temperature in the evaporator $\left(T_{\mathrm{VR}}\right)$ as a function of the remaining weight of the liquid will follow that of Figure 2 for the greater part of the experiment. Toward the end $T_{\mathrm{VR}}$ sharply rises to $600{ }^{\circ} \mathrm{C}$. Figure 4 shows the products as collected in a type I experiment, split up according to the point of recovery. The amount of hydrogen chloride dissolved in the cold trap was calculated using the data of Danov and Golubev (1968). The overall conversion of the EDC in the VCM by-product is about 85 wt \%; of 1,1,2-trichloroethane, 75 wt $\%$.

The composition of the condensate from the partial condensor, as collected in a type I experiment, varies with time as shown in Figure 5.

We calculated an overall rate constant for the gas-phase pyrolysis of the EDC rich feed, assuming an isothermal, ideal tubular reactor and first-order decomposition kinetics: $k_{1}=0.018 \mathrm{~s}^{-1}$ at $545{ }^{\circ} \mathrm{C}$. Variation of $T_{\mathrm{GR}}$ showed that the activation energy was about $40 \mathrm{kcal} \mathrm{mol}^{-1}$. Both rate constant and activation energy are comparable with results from pure compounds: in Figure 1 compare line $\mathrm{j}$ with the others.

When the condensate from the partial condensor PC is recycled to the evaporator VR, as is done in the type II and III experiments, an overall conversion of EDC and 1,1,2trichloroethane of over $95 \%$ is obtained. Along with the unreacted material unsaturated products, especially dichloroethenes (Figure 4) are recycled to the reactor system. The effect of recycling on the total product distribution of the combined gas- and liquid-phase pyrolysis is shown in Figure 6

Recycling increases the yield of solid residue in the liquid-phase reactor. In contrast with the pyrolysis product of chlorinated PVC this residue did not show any porosity even after heat treatment at $800^{\circ} \mathrm{C}$. In the type II experiment there was also a marked increase in the fouling of the gas phase reactor: $1 \mathrm{wt} \%$ of the feed was recovered as a film deposit from the gas-phase reactor and tar formation above the reactor was considerable (estimated $4 \%$ ). The low yield of 1,2-dichloroethenes suggests that these compounds, when circulating through the reaction system, are involved in the fouling of the gas-phase reactor. This is in agreement with the observation of Goodall and Howlett (1956) that monochloroacetylene, formed by decomposition of dichloroethene in the gas phase, polymerizes rapidly.

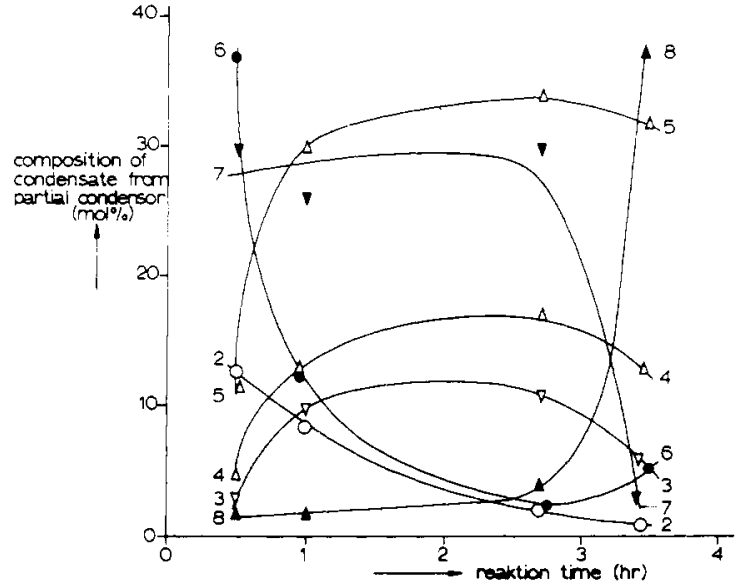

Figure 5. Composition of the collected condensate from the partial condensor PC as a function of reaction time for the type I experiment of Figure 4. Please refer to the number code of the caption of Figure 4

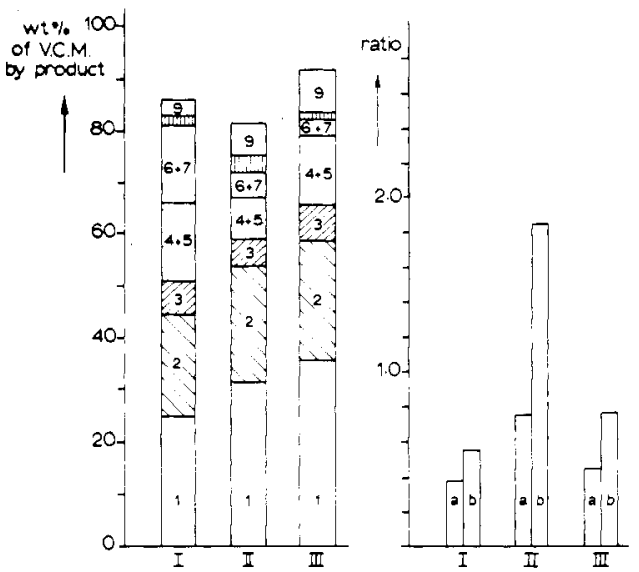

Figure 6. Total product distributions of the combined gas- and liquid-phase pyrolvsis. $T_{\mathrm{GR}}=545^{\circ} \mathrm{C}$. Number code: see the caption of Figure 4.J = tar formation. I, without recycling of condensate PC; $T_{\mathrm{VR}}=95-600{ }^{\circ} \mathrm{C}$; II, without recycling of condensate PC; $T_{\mathrm{VR}}=95-230^{\circ} \mathrm{C}$; III, with recycling of the condensate $\mathrm{PC}$ and $0.63 \% \mathrm{AlCl}_{3}$ added to the VCM by-product; $T_{\mathrm{VR}}=95-600^{\circ} \mathrm{C}$. a, ratio 1,1-1,2-dichloroethene; $b$, ratio trans-:cis 1,2-dichloroethene. Please refer to the letter code of the caption of Figure 3.

Recycling of the condensate from the partial condensor also results in an increase of the overall trans/cis-1,2-dichloroethene ratio in the product distribution, as shown in Figure 6. In the type I experiment the trans/cis ratio is close to the thermodynamic equilibrium: 0.6 (Pitzer and Hollenberg, 1954) due to the rapid isomerization of 1,2-dichloroethene as it is formed in the gas-phase pyrolysis (Jones and Taylor, 1940). Due to the higher boiling point of the cis isomer $\left(60^{\circ} \mathrm{C}\right)$ in comparison with the trans isomer $\left(47^{\circ} \mathrm{C}\right)$, a relative high fraction of the cis isomer is collected in the partial condensor: trans/cis ratio $<0.5$ (see Figure $4)$. Because the equilibrium is again rapidly established in the gas-phase reactor when the condensate is recycled, the overall trans/cis in the type II and III experiments ratio lies above that of the equilibrium.

If, in a type III experiment, finely powdered $\mathrm{AlCl}_{3}$ is added to the VCM by-product feed, the yield of solid residue in the liquid-phase reactor is higher than in a type II experiment, due to the polymerization effect of $\mathrm{AlCl}_{3}$. This can be seen in Figure 6, especially when the lower maximum temperature $T_{\mathrm{VR}}$ in the type II experiment is taken into account. No increased fouling of the reactor was observed compared to type I experiments. This supports the 


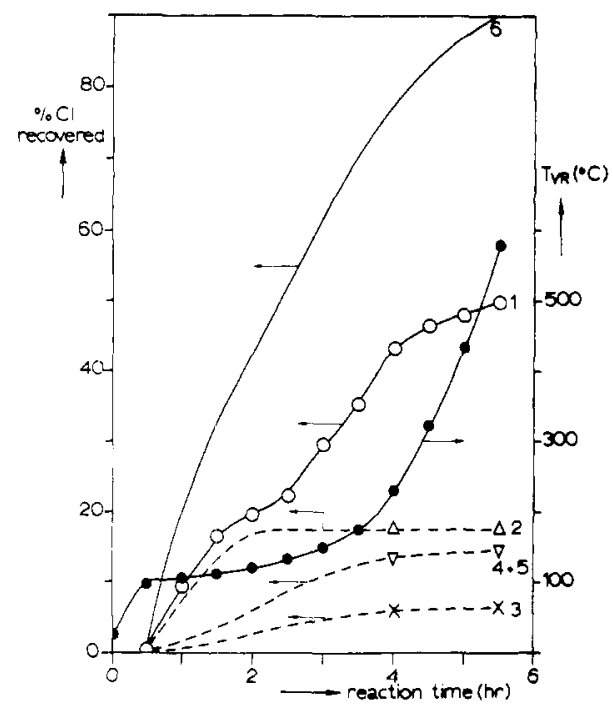

Figure 7. Percent of chlorine recovered from the VCM by-product in a type III experiment $\left(0.63 \% \mathrm{AlCl}_{3}\right.$ added $)$ and the temperature in the evaporator/liquid-phase reactor $\left(T_{\mathrm{VR}}\right)$ as a function of reaction time. 1 , as hydrogen chloride; 2 , as vinyl chloride; 3 , as 1,1 -dichloroethene; 4 and 5 , as 1,2-dichloroethene; 6 , total wt \% of chlorine recovered in the form of these products.

view that tar and coke formation is mainly caused by the presence of unsaturated chlorinated compounds. Toward the end of the type III experiment of Figure $6\left(T_{\mathrm{VR}}=\right.$ $\left.450-600{ }^{\circ} \mathrm{C}\right)$ small amounts of cracking products $(0.1 \%)$ such as hydrogen and methane were produced. Figure 7 give the $\%$ of the chlorine recovered from the VCM byproduct and the $T_{\mathrm{VR}}$ as a function of the reaction time in the type III experiment.

In all our experiments the chlorine contents of the carbon deposit in the gas-phase reactor were low: $<5 \%$. The chlorine contents of the solid residue in the liquid-phase reactor depended on the maximum temperature reached: $26 \%$ at $T_{\mathrm{VR}}=230{ }^{\circ} \mathrm{C}, 7.4 \%$ at $T_{\mathrm{VR}}=600^{\circ} \mathrm{C}$ and $2.0 \%$ at $T_{\mathrm{VR}}=700^{\circ} \mathrm{C}$.

To check the formation of higher molecular compounds in the liquid-phase reactor in the presence of larger amounts of $\mathrm{AlCl}_{3}$, we brought together the condensate from the partial condensor (Figure 4, second column) with $11 \mathrm{wt}$ $\% \mathrm{AlCl}_{3}$ powder, under reflux and constant stirring. After $46 \mathrm{~h}$ at $70^{\circ} \mathrm{C}$ the reflux cooler was removed and the reaction vessel was heated for $4.5 \mathrm{~h}$ until a temperature of 700 ${ }^{\circ} \mathrm{C}$ was reached, thus distilling off the reaction products. Of these products, $23 \mathrm{wt} \%$ formed a fraction bp $70-250^{\circ} \mathrm{C}$, $20 \%$ a fraction bp $250-350^{\circ} \mathrm{C}, 10 \%$ was collected as hydrogen chloride, and $24 \%$ remained as a solid residue after cooling to room temperature. Above $350{ }^{\circ} \mathrm{C}$ considerable amounts of hydrogen and methane were detected.

The main reactions that take place in our reaction system are shown in the following scheme.

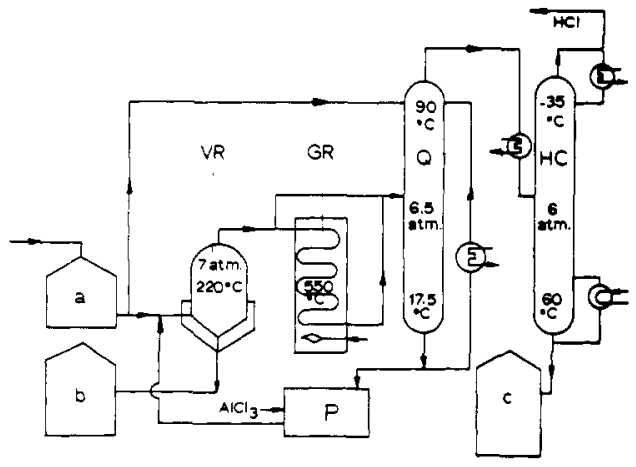

Figure 8. Flow sheet of the possible semicontinuous combined gas- and liquid-phase pyrolysis of the VCM by-product on an industrial scale: VR = evaporator/liquid phase reactor; $\mathrm{GR}=$ gasphase reactor furnace; $Q=$ quenching column; $H C=$ hydrogen chloride column; $a=$ tank for VCM by-product; $b=$ tank for heavies; $\mathrm{c}=\operatorname{tank}$ for vinyl chloride and chlorinated $\mathrm{C}_{2}$; and $\mathrm{P}=\mathrm{re}-$ actor for polymerization.

\section{Considerations about Industrial Application}

Using the results of the above described experiments and literature, we considered the industrial application of our combined gas- and liquid-phase pyrolysis of VCM products. The proposed installation, of which a flow sheet is shown in Figure 8, should be operated at 6-7 atm pressure to decrease the installed volume, to achieve a better heat transport in the gas phase and still have a workable temperature in the evaporator. Because of the absence of water, no appreciable corrosion is to be expected when stainless steel is used as a construction material.

An important point in the process is the degree of coke formation in the gas-phase reactor. Because chloroethenes are the main precursors of the coke formation, it seems appropriate to maximize their polymerization to avoid their recycling, by installation of a separate polymerization tank P. As shown in our experiments, higher molecular compounds are formed from chloroethenes with chloroethanes under the influence of a metalchloride such as $\mathrm{AlCl}_{3}$.

Considerations of the prevention of coke formation by choosing both the optimal dimensions of the gas-phase reactor and the optimal process pressure are given in a patent of the Goodrich Company (1963). By optimizing operating conditions and through careful reactor design it should be possible to lower the deposit of carboneous material in the gas-phase reactor by a factor of 3 with respect to that in our experiments of type III. In that case about $1 \mathrm{~g}$ of carbon would be deposited per $\mathrm{kg}$ of feed pyrolyzed. It is then possible to carry out gas-phase pyrolysis continuously for several days in a weekly cycle, at constant temperature $T_{\mathrm{VR}}$ in the evaporator. During this period the higher boiling material in the VCM by-product feed, together with that formed in the polymerization tank, is stored.

The rest of the week this higher boiling material is pyro-

$$
\begin{aligned}
& \text { gas phase: }\left\{\begin{array}{l}
\mathrm{ClCH}_{2}-\mathrm{CH}_{2} \mathrm{Cl} \stackrel{-\mathrm{HCl}}{\longrightarrow} \mathrm{CH}_{2}=\mathrm{CHCl} \\
\mathrm{ClCH}_{2}-\mathrm{CHCl}_{2} \begin{array}{c}
\frac{-\mathrm{HCl}}{70 \%} \\
\frac{-\mathrm{HCl}}{30 \%}
\end{array} \mathrm{CH}_{2}=\mathrm{CCl}_{2}
\end{array}\right. \\
& \begin{array}{l}
\text { gas and } \\
\text { liquid } \\
\text { phase: }
\end{array} \quad\left\{\begin{array}{l}
3 \mathrm{CCl}_{2}=\mathrm{CHCl} \stackrel{-\mathrm{HCl}}{\longrightarrow} \mathrm{C}_{6} \mathrm{Cl}_{6} \quad \text { (Goodall and Howlett, 1954) } \\
\mathrm{CHCl}_{2}-\mathrm{CHCl}_{2} \stackrel{\mathrm{HCl}}{\longrightarrow} \mathrm{CCl}_{2}=\mathrm{CHCl}
\end{array}\right. \\
& \text { liquid } \\
& \int \mathrm{di} \text { - and trichlorobutanes } \stackrel{-\mathrm{HCl}}{\longrightarrow} \text { (chlorinated) butadienes } \longrightarrow
\end{aligned}
$$


lyzed batchwise in the liquid phase at $T_{\mathrm{VR}}=220-600^{\circ} \mathrm{C}$, in the presence of $\mathrm{AlCl}_{3}(1-10 \%)$. Meanwhile the gas-phase reactor can be cleaned by burning off the carbonaceous deposit with air. In this way about 45 wt $\%$ of the VCM byproduct feed could be converted into hydrogen chloride, $35 \%$ is obtained as a mixture of VCM and 1,1-dichloroethene, and $20 \%$ forms a high molecular residue with a chlorine content of about $10 \%$, which, for example, could be used in road construction.

Although many aspects of the process will have to be detailed according to results of further investigations, rough calculations, based on a 12000 ton/year installation integrated in a VCM plant employing oxychlorination, indicate that the value of the products can at least compensate the capital and operating costs of the process.

\section{Conclusions}

The VCM by-product sample we examined contained 70 wt \% chlorine and was a mixture of at least 16 partially chlorinated $\mathrm{C}_{2}$ and $\mathrm{C}_{4}$ compounds and higher molecular polymers and tars. The main components were 1,2-dichloroethane (EDC, $37 \mathrm{wt} \%$ ) and 1,1,2-trichloroethane (43 wt $\%)$. By means of a batchwise combined gas- and liquidphase pyrolysis at $1 \mathrm{~atm}, 54 \%$ of the chlorine present in the VCM by-product could be recovered as dry hydrogen chloride, $18 \%$ as vinyl chloride, $27 \%$ as chlorinated $\mathrm{C}_{2}$ hydrocarbons, and only less than $1 \%$ remained in the solid residue of the pyrolysis.

The first stage of the pyrolysis $T_{\mathrm{VR}}=95-150^{\circ} \mathrm{C}$ ) consists mainly of gas-phase dehydrochlorination of EDC and 1,1,2-trichloroethane, producing, besides hydrogen chloride, vinyl chloride and three dichloroethene isomers, as expected. For the decomposition of the EDC rich vapor feed we calculated an overall first-order rate constant 0.018 $\mathrm{s}^{-1}$ at $545^{\circ} \mathrm{C}$. The rate of the process cannot be expected to depend largely on the presence of inhibitors such as carbon tetrachloride or aromatics because this value suggests that the monomolecular decomposition prevails. The activation energy was about $40 \mathrm{kcal} \mathrm{mol}^{-1}$.

At $T_{\mathrm{VR}}=150^{\circ} \mathrm{C}$ the remaining VCM by-product starts decomposition in the liquid phase. Besides dehydrochlorination, a complex of condensation and polymerization reactions occurs in which recycled products of the gas-phase pyrolysis are also involved. The chlorine contents of the final residue in the liquid-phase reactor depend on the maximum temperature reached: at $T_{\mathrm{VR}}=600^{\circ} \mathrm{C},<7 \mathrm{wt} \%$ $\mathrm{Cl}$. The amount of higher molecular material formed can be increased by the addition of $\mathrm{AlCl}_{3}$.
The amount of solid residue and the overall conversion of VCM by-product are considerably increased by recycling unreacted material and part of the unsaturated products of the gas-phase pyrolysis to the evaporator annex liquidphase reactor. When, however, the polymerization of these recycled products is not large enough, the fouling of the gas-phase reactor will increase. In all our experiments at least $0.5 \%$ of the VCM product feed was recovered as coke from the gas-phase reactor. The chlorine contents of this deposit were always $<5 \mathrm{wt} \%$.

For technical application separate polymerization of unsaturated compounds in the recycle stream seems necessary. This can be done in a reactor at the temperature of the bottom of the quenching column, under the influence of metal chlorides.

\section{Acknowledgment}

The authors wish to acknowledge Cindu-Key \& Kramer N.V. (The Netherlands) for the financial support provided for this project.

\section{Literature Cited}

Barton, D. H. R., J. Chem. Soc., 148 (1949).

Barton, D. H. R., Howlett, K. E., J. Chem. Soc., 165 (1949).

Barton, D. H. R., Howlett, K. E., J. Chem. Soc., 2033 (1951).

Barton, D. H. R., Onyon, P. F., J. Am. Chem. Soc., 72, 988 (1950).

Berticat, Ph., et al., J. Chim. Phys., Physicochim. Biol., 67 (1), 176 (1970).

Danov, S. M., Golubev, Yu. D., Khim. prom., 44 (2), 116 (1968).

Goodall, A. M., Howlett, K. E., J. Chem. Soc., 2599 (1954).

Goodall, A. M., Howlett, K. E., J. Chem. Soc., 3092 (1956a)

Goodall, A. M., Howlett, K. E., J. Chem. Soc., 2640 (1956b)

Goodrich Company, British Patent 938 824, Oct 9 (1963)

Hartmann, H., et al., Z. Phys. Chem. (Frankfurt am Main), 42, 329 (1964).

Heydtmann, H., Rinck, G., Z. Phys. Chem. (Frankfurt am Main), 28, 85 (1961).

Holbrook, K. A., Marsh, A. R. W., Trans. Faraday Soc., 63, 643 (1967).

Jones, J. L., Taylor, R. L., J. Am. Chem. Soc., 62, 3480 (1940).

Kapralova, G. A., Semenov, N. N., Russ. J. Phys. Chem. 37, 35, 156 (1963).

Kelen, T., Nagy, T. T., Fudos, F., React. Kin. Catal. Lett. 1 (1), 93 (1974).

Maccoll. A., Chem. Rev., 69 (1), 33 (1969).

Moller, H., et al., Angew. Chem., 83 (6), 185 (1971).

Pitzer, K. S., Hollenberg, J. L., J. Am. Chem. Soc., 76, 1493 (1954).

Prins, H. L., Rec. Trav. Chim. Pays Bas, 56, 119 (1937).

Rothan, R. N., Sims, E. W., Chem. Ind. (London), 830 (1970).

Shelton, L. G., et al. "High Polymers", Vol. XXIV, Pt. 3, pp 1205-1289, H.

Mark, Ed., Wiley, New York, N.Y., 1971.

Stauffer Chemical Co., Eur. Chem. News, 26 May, 26 (1972); 21 July, 22 (1972); 20 July, 22 (1973).

Swinbourne, E. S., "Comprehensive Chemical Kinetics", Vol. 5, pp 149-

233. Ch. Bamford and C. F. H. Tipper, Ed., Elsevier, Amsterdam, 1972.

Teramoto, K., et al., Kogyo Kagaky Zasshi, 67, 460 (1964).

Urone, P., et al., Anal. Chem., 34, 476 (1962).

Williams, R. J., J. Chem. Soc., 312 (1953).

Zilberman, E. N., et al., Dokl. Chem., 174, 536 (1967).

Zilberman, E. N., et al., J. Polym. Sci., A-1, 8, 2325 (1970).

Received for review July 8, 1975 Accepted December 15, 1975 